\title{
PRECARIZAÇÃO DO TRABALHO FEMININO: a realidade das mulheres no mundo do trabalho
}

\author{
Sara Diniz Nascimento \\ Instituto Federal de Educação, Ciência e Tecnologia do Maranhão (IFMA)
}

PRECARIZAÇÃO DO TRABALHO FEMININO: a realidade das mulheres no mundo do trabalho

Resumo: Abordagem sobre a precarização do trabalho feminino no contexto a reestruturação produtiva do capital. Enfatiza as desigualdades históricas construídas entre o masculino e o feminino e a divisão sexual do trabalho e as incidências desses processos na inserção e realidade das mulheres no mundo do trabalho. Destaca que a intensificação de mudanças nas formas contemporâneas de organização da produção, tem gerado um contexto onde as condições de trabalho tornam-se cada vez mais flexíveis. Ressalta, nesse sentido, o aumento da precarização dos postos de trabalho, evidenciado na instabilidade dos empregos, na informalização, no trabalho subcontratado e em tempo parcial, e, ainda, na perda de direitos e garantias trabalhistas historicamente construídas. Conclui que essas mudanças têm repercutido fortemente sobre a classe trabalhadora, adquirindo grande peso na inserção e condições de trabalho do segmento feminino, pois são as mulheres que mais sofrem com todo esse processo.

Palavras-chave: Reestruturação produtiva, precarização, trabalho feminino.

PRECARIOUS FEMININE WORK: the reality of women in the working world

Abstract: This article discusses about the precariousness of female employment in the context of productive capital restructuring. Emphasizes the socio - historical inequalities built between masculine and feminine, the sexual division of labor, and the incidence of this processes on the integration of women in the working world. Highlights the intense process of change in the world of work, based on contemporary forms of production organization, which has created a context where working conditions become increasingly flexible. In this sense, there is an increasing casualization of jobs, evidenced in the instability of jobs in the informal, the subcontracted work and part-time, and even the loss of labor rights and guarantees historically constructed. These changes are reflected heavily on the working class, getting a great weight on entering and working conditions of female segment because it is the women who suffer most from this whole process. Key words: Productive restructuring, precariousness, feminine work. 


\section{INTRODUÇÃO}

O intenso processo de mudanças no mundo do trabalho, baseado nas formas contemporâneas de organização da produção, tem gerado um contexto onde as condições de trabalho tornam-se cada vez mais flexíveis. Nesse sentido, há um aumento da precarização dos postos de trabalho, evidenciado na instabilidade dos empregos, na informalização, no trabalho subcontratado e em tempo parcial, e ainda na perda de direitos e garantias trabalhistas historicamente construídas.

Essas mudanças têm repercutido fortemente sobre a classe trabalhadora, adquirindo um grande peso sobre a inserção e condições de trabalho do segmento feminino, pois são as mulheres que mais sofrem com todo esse processo. O crescimento do desemprego, o aumento dos postos de trabalho de subcontratação, temporário, com jornada parcial e com menores rendimentos concentram, principalmente, a mão de obra feminina.

Essa realidade é permeada, fundamentalmente, pelas desigualdades de gênero construídas social e culturalmente, configurando as identidades de masculino e feminino, bem como os espaços a serem ocupados pelos sexos, ou seja, a definição do espaço privado para as mulheres e esfera pública para os homens.

A construção social das relações de gênero se fundamenta no patriarcado que segundo Santos e outros (2007, p. 68), embasa

[...] a organização da vida de muitas sociedades, norteadas pela ideia de que existiria uma superioridade física [...], produtiva, artística e intelectual dos homens em relação às mulheres.

Dessa forma, as oportunidades e condições de trabalho das mulheres são expressas pelo patriarcalismo e pela divisão sexual do trabalho que naturalizam as diferenças biológicas entre os sexos e determinam o papel a ser ocupado por homens e mulheres no conjunto das forças produtivas. Segundo Hirata (2002, p. 281):

A divisão sexual do trabalho é sempre indissociável das relações entre homens e mulheres, que são relações desiguais, hierarquizadas, assimétricas e antagônicas [...] de exploração e de opressão entre duas categorias de sexo construídas socialmente.

Nesse sentido, a divisão sexual do trabalho sustenta e estrutura as relações desiguais de gênero; essas desigualdades entre os sexos, geradas pela sociedade, são incorporadas pelo capital como mecanismo de elevação dos lucros e domínio ideológico e social. Para Nogueira (2004, p.18):
O mundo do trabalho acentuou profundamente a divisão sexual do trabalho, reservando para as mulheres espaços específicos que, na maioria das vezes, se caracterizavam pela inferioridade hierárquica, pelos salários menores e por atividades adaptadas a suas capacidades inatas.

Assim, a ocupação de postos de baixa capacidade técnica e de menor prestígio na hierarquia profissional, desnivelamento salarial e falta de acesso à qualificação, demonstram as desigualdades de oportunidades no mundo do trabalho, onde as mulheres estão expostas à informalidade, ao desemprego e às piores remunerações.

Para construção deste artigo, utilizamos a pesquisa bibliográfica a partir do levantamento de referências teóricas sobre a temática, através desse procedimento podemos interpretar e dialogar com as obras referenciadas.

Dessa forma, este texto tem por objetivo, discutir sobre a realidade das mulheres no mundo do trabalho diante do processo de Reestruturação Produtiva. No primeiro momento traça um breve histórico sobre a inserção das mulheres no mundo do trabalho, e como que o advento do capitalismo molda essa inserção. Em seguida, aborda sobre o processo de reestruturação produtiva do capital e as implicações para os trabalhadores, em especial para as mulheres. E por fim, apresentamos as considerações finais.

\section{A INSERÇÃO DAS MULHERES NO MUNDO DO TRABALHO}

Em diferentes épocas e sociedades as mulheres vêm desenvolvendo algum tipo de trabalho. Nas economias pré-capitalistas as mulheres das classes populares trabalhavam na agricultura, na manufatura, no comércio, etc. e seu trabalho, parafraseando Saffioti (1976), desempenhava um papel importante para a subsistência de sua família e para a geração da riqueza social.

Entretanto, em virtude da cultura patriarcal, onde a mulher deve apresentar um comportamento submisso ao homem, o papel desenvolvido por ela dentro do conjunto das funções econômicas se define como subsidiário e de menor relevância quando comparado ao trabalho masculino. Esta constatação se afirma no desenvolvimento das relações de produção e reprodução da vida social arraigadas na divisão social e na divisão sexual do trabalho, onde se atribui funções a homens e mulheres de acordo com o conceito sociocultural de feminino e masculino; tais relações são ainda, permeadas por questões de gênero, classe e raça/ etnia. 


\begin{abstract}
A divisão sexual do trabalho assume formas conjunturais e históricas, é construída como prática social, ora conservando tradições que ordenam tarefas masculinas e tarefas femininas [...], ora criando modalidades da divisão sexual das tarefas. A subordinação de gênero, a assimetria nas relações de trabalho masculinas e femininas manifesta-se não apenas que definem a qualificação das tarefas, nos salários, na disciplina do trabalho. A divisão sexual do trabalho não é tão somente uma consequência da distribuição do trabalho por ramos ou setores de atividade, senão também o princípio organizador da desigualdade no trabalho (LOBO apud CARLOTO, 2002).
\end{abstract}

A divisão sexual do trabalho ao distribuir atividades de acordo com o sexo expressa sinais de hierarquia e opressão de um sexo sobre o outro, pois as funções ditas masculinas aparecem como superiores às femininas, já que as funções femininas carregam a atribuição da inferioridade e complementaridade às masculinas. Assim, a divisão sexual do trabalho entendida como fator histórico, está estruturada a partir do princípio do trabalho masculino ser superior ao feminino, o que reforça a hierarquia nas relações de poder baseadas no sexo. Desse modo, conforme Hirata (2002, p. 280):

A divisão sexual do trabalho baseia-se na ideia de uma relação antagônica entre homens e mulheres. [Ela] é considerada como um aspecto da divisão social do trabalho, e nela a dimensão opressão/ dominação está fortemente contida.

Nesse sentido, a acepção de trabalho subsidiário provoca históricas e intensas barreiras ao emprego do trabalho feminino, perpassado pela ocupação de posições subalternas e menos compensatórias.

Com a instauração do modo capitalista de produção as barreiras impostas às mulheres, no que se refere à inserção nas funções produtivas tornam-se maiores e mais complexas, pois esse sistema de produção e reprodução social tende a criar mecanismos de atenuação das contradições geradas pela diferenciação de classes sociais. Um desses mecanismos é a naturalização das diferenças e desigualdades de sexo e raça, tornando normal a inferiorização de segmentos sociais em detrimento de outros: a inferiorização da mulher pela supervalorização da figura masculina, que se complexifica quando se trata da mulher negra. De acordo com Saffioti (1976, p. 35):

Oaparecimento docapitalismose dá, pois em condiccões extremamente adversas à mulher. No processo de individualização inaugurado pelo modo de produção capitalista, a mulher contaria com uma desvantagem social de dupla dimensão: no nível superestrutural era tradicional uma subvalorização das capacidades femininas traduzidas em termos de mitos justificadores da supremacia masculina e, portanto, da ordem social que a gerara; no plano estrutural, à medida que se desenvolvam as forças produtivas, a mulher vinha sendo progressivamente marginalizada das funções produtivas, ou seja, perifericamente situada no sistema de produção.

A criação sociocultural de uma incapacidade feminina impede a realização plena da mulher no trabalho, impossibilitando-a de extrapolar o lócus privado e alcançar os espaços públicos da vida social. A inculcação de possíveis virtudes femininas na sociedade, como passividade, submissão, doçura e fragilidade, leva a criação de uma incompatibilidade entre a feminilidade e a produtividade, o discurso criado é o da superposição das obrigações domésticas e maternais sobre qualquer atividade profissional das mulheres. Contudo, a sociedade capitalista necessita em seu processo de acumulação, do trabalho feminino, pois ao aproveitar imensas massas de mão de obra feminina há uma elevação na absorção da maisvalia. Assim, o emprego do trabalho das mulheres no processo industrial tem por objetivo utilizar trabalho barato e elevar os lucros.

Conforme Nogueira (2004, p. 13):

[...] se por um lado o ingresso do trabalho feminino no espaço produtivo foi uma conquista da mulher, por outro lado permitiu que o capitalismo ampliasse a exploração da força de trabalho, intensificando-a através do universo do trabalho feminino.

Dessa forma, o desenvolvimento capitalista que ganhou força com a Revolução Industrial, isto é com a introdução da maquinaria no processo produtivo, propiciou a maior inserção de mão de obra feminina. Entretanto, essa inserção se dá em meio a ocupações de baixa capacidade técnica e subalternizada, possíveis de serem conciliadas às atividades domésticas o que expressa à dupla jornada de trabalho vivenciada pelas mulheres. A esse respeito, Nogueira (2004, p. 8) afirma que:

No século XIX com o desenvolvimento da Revolução Industrial Inglesa, ocorre um monumental desenvolvimento tecnológico voltado para a produção de mercadorias e a acumulação de capital. Nesse processo, verificamos uma intensificação da inserção feminina no mundo do trabalho, já que a maquinaria pode dispensar 0 uso da força muscular [...] E, junto com o advento da maquinaria, deu-se o ingresso definitivo da mulher no mundo do trabalho. 
Contudo, segundo Scott (apud NOGUEIRA, 2004, p. 18),

[...] os trabalhos de mulheres eram aqueles que se adaptavam mais as suas capacidades físicas e aos seus níveis inatos de produtividade.

E isso revela uma segregação sexual no mercado de trabalho, pois além das mulheres estarem inseridas em postos de baixa capacidade técnica nas indústrias, no setor de serviços e comércio elas ocupavam cargos adaptados às suas capacidades inatas, como por exemplo, de "[...] secretárias e escriturarias nas repartições públicas, vendedoras de selos nos correios, enfermeiras e professoras." (NOGUEIRA, 2004, p. 18).

Nesse sentido, há a comprovação da criação de uma natural divisão sexual do trabalho, existindo assim, noções de trabalho relacionadas às profissões ou cargos que devem ser ocupados pelas mulheres. A ocupação de postos de trabalho subalternos e a menor qualificação profissional das mulheres revelam e reforçam o preconceito e a discriminação existentes contra elas na sociedade, em especial, no mundo do trabalho. Como ressalta Saffioti (1976, p. 47),

A valorização da força física do homem serve de justificativa à hierarquização dos sexos, [já que os] preconceitos de raça e sexo desempenham, pois, um papel relevante quer na conservação do domínio do homem branco, quer na acumulação do capital.

O preconceito e a discriminação são ratificados pelos fatores biológicos de diferenças entre os sexos utilizados para justificar a incapacidade profissional das mulheres, tais fatores de ordem natural são metamorfoseados em diferenças sociais. Um exemplo, diz respeito à redução do trabalho das mulheres por conta da maternidade, a descontinuidade do trabalho feminino fornece argumentos aos empregadores para reforçar a subalternidade na hierarquia das posições, bem como a preferência de mão de obra masculina nos cargos de chefia que requisitam maior responsabilidade.

Para ratificar esse argumento de subalternidade e incapacidade profissional do segmento feminino, os empregadores, conforme ressalta Araújo (2007, p. 82), subsidiam-se na seguinte afirmação:

No caso das mulheres, o argumento comumente utilizado para justificar a sua não contratação, ou demissão, diz respeito aos gastos com os direitos relativos à maternidade e ao cuidado com os filhos, os quais aumentariam o custo de seu trabalho em relação aos homens.
Importa ressaltar, que a sociedade necessita para sua sobrevivência do nascimento e socialização de novas gerações, o que revela que a maternidade não pode ser encarada como problema exclusivo das mulheres para continuidade de sua atividade profissional. Portanto, é fundamental a criação de mecanismos que possibilitem a realização de atividades ocupacionais das mulheres, como é o caso da licença maternidade.

E ainda, é uma falácia dizer que com a maternidade aumentam-se os gastos dos empregadores em relação ao trabalho feminino, pois, segundo Araújo (2007), pesquisa recentemente realizada pela Organização Internacional do Trabalho (OIT), em 5 países da América Latina ${ }^{1}$, mostra que esta visão de custo maior do trabalho feminino é mais um mito do que um dado, isto porque o custo do salário não recai diretamente sobre os empregadores, mas é pago pelo sistema de seguridade social ou por fundo público dos países pesquisados.

Nesse sentido, a subalternidade, o preconceito e a discriminação que permeiam a inserção das mulheres em atividades laborativas constituem-se mecanismos de impossibilidade da realização e emancipação destas no mundo do trabalho, pois esta inserção se dá em atividades de menor prestígio e responsabilidade acompanhada de uma má remuneração. Este é um cenário produzido a partir da construção social e cultural de espaços exclusivos do feminino e masculino, assim o espaço da casa, o mundo privado é considerado o lugar natural da mulher, e a sua entrada na esfera pública por consequência do trabalho, ou de qualquer outro tipo de prática social e política é marcada pela divisão sexual da sociedade. Assim, as relações sociais de sexo e a divisão sexual do trabalho são indissociáveis e funcionam como práticas que segregam as mulheres tanto na esfera reprodutiva quanto na produtiva. Conforme apresenta Hirata (2002, p. 277),

A exploração por meio do trabalho assalariado e a opressão do masculino sobre o feminino são indissociáveis, sendo a esfera da exploração econômica - ou das relações de classe - aquela em que simultaneamente, é exercido o poder dos homens sobre as mulheres.

Portanto, a condição das mulheres no mundo do trabalho é perpassada pela dimensão de classe, raça/etnia e pelas relações de gênero, que em constante inter-relação desenham as representações do feminino no trabalho.

Dessa forma, a inserção massiva das mulheres no mundo do trabalho, a partir das mudanças econômicas e sociais resultantes da Revolução industrial, não representou consubstancialmente uma revolução na vida destas, ou seja, não rompeu com a acepção do 
papel feminino construído socialmente, cabendo às mulheres articular os papéis familiares e as atividades profissionais. Isto reproduz uma imagem da mulher trabalhadora perpassada pelo papel do feminino ligado ao doméstico, aos cuidados com a casa e com os filhos. Em relação a tal imagem, Carloto (2002) apresenta:

A identidade da mulher como trabalhadora, portanto, vai estar sempre associada a seu papel de reprodutora. Essa imagem básica, originária da mulher família, mãe, dona-de-casa vai estar sempre na frente. O trabalho, por exemplo, é tratado no masculino e o trabalho produtivo é feito pelos trabalhadores. É ao homem que se associa a imagem de trabalhador, de provedor da família. Essa imagem da mulher vai trazer limitações a uma adequada colocação no mundo do trabalho.

Essa imagem do feminino, construída e repassada aos indivíduos desde as primeiras etapas de socialização, baseadas na definição do espaço público como lócus masculino e espaço privado como habitat feminino, determinam as oportunidades e a forma de inserção dos homens e das mulheres no mundo do trabalho, sendo o ingresso das mulheres atravessado pelo aspecto da subvalorização, o que impossibilita a colocação das mulheres no mercado de trabalho de forma digna e igualitária.

\section{REESTRUTURAÇÃO PRODUTIVA E PRECARIZAÇÃO DO TRABALHO FEMININO}

Como resposta à crise estrutural devido ao esgotamento do padrão de acumulação baseado no fordismo/taylorismo ${ }^{2}$, iniciou-se um processo de reordenamento do capital e de seu sistema ideológico e político, traduzido no advento do neoliberalismo, cujas características mais evidentes são a desregulamentação e flexibilização das condições de trabalho, privatização de empresas estatais e perda de direitos e garantias trabalhistas.

Portanto, a partir da década de 1970, a flagrante crise do padrão de acumulação fordista/ taylorista requisita do capital um processo de reestruturação com vistas a recuperar o seu ciclo produtivo e seu projeto de dominação social. Assim, como afirma Nogueira (2004, p. 32),

O capitalismo, no decorrer da história, metamorfoseou-se de inúmeras maneiras. Mas a partir de 1973, esse modo de produção desencadeou um processo intenso de reestruturação das relações sociais que constituem o capital.
Desse modo, o quadro crítico do capital na década de 1970, provoca intensas modificações econômicas, sociais, políticas e ideológicas que repercutem sobre os trabalhadores e trabalhadoras, ou pela classe que vive do trabalho como designa Antunes (2002). A expressão classe que vive do trabalho é utilizada pelo autor para demarcar a contemporaneidade e amplitude à classe trabalhadora. Como o próprio Antunes (2002, p. 103104) afirma:

Uma noção ampliada de classe trabalhadora inclui, então, todos aqueles e aquelas que vendem sua força de trabalho em troca de salário, incorporando além do proletariado industrial, dos assalariados do setor de serviços, também o proletariado rural, que vende sua força de trabalho para o capital [...] o proletariado precarizado, o subproletariado moderno, part time, [...] os trabalhadores terceirizados e precarizados, [...] os trabalhadores assalariados da chamada 'economia informal', que muitas vezes são indiretamente subordinados ao capital além dos trabalhadores desempregados, expulsos do processo produtivo e do mercado de trabalho pela reestruturação do capital e que hipertrofiam o exército industrial de reserva na fase de expansão do desemprego estrutural.

Nesse sentido, a reestruturação do capital ocorreu de forma superficial, já que não modificou a base da acumulação (exploração da classe trabalhadora), ou seja, o que aconteceu foi uma transição do modo de produção fordista/ taylorista para novas formas de acumulação - acumulação flexível. O desemprego em nível estrutural, a precarização do trabalho e a destruição dos recursos naturais em escala global são pontos constitutivos dessa fase de reestruturação produtiva.

Assim, para reverter o cenário de crise; recuperar seu processo produtivo e também o seu projeto societal, o capital deflagra várias transformações através das formas de acumulação flexível, das formas de gestão organizacional, do avanço tecnológico, enfim de um novo padrão produtivo - o toytismo (organização do trabalho que nasceu na fábrica Toyota, no Japão pós-45, inventada pelo vice-presidente Taiichi Ohno).

Essas transformações mostram a reorganização do sistema capitalista, com a introdução de novas formas de dominação social, buscando recuperar a hegemonia nas diversas esferas de sociabilidade, principalmente através do culto ao individualismo. Exacerbando-se assim, um novo estilo de organização industrial e também da relação capital-trabalho, que exige um perfil de trabalhador mais qualificado, participativo, multifuncional e polivalente. Esse novo padrão de acumulação é marcado pela nova divisão de 
mercados, desemprego, divisão global do trabalho, fechamento de unidades produtivas, reorganização financeira e tecnológica, capital volátil entre outros. Um dos pressupostos do toyotismo é a qualidade total tão difundida no mundo empresarial moderno como forma de reposição do processo de valorização do capital. A qualidade total se expressa pela negação da durabilidade dos produtos, quanto mais qualidade as mercadorias aparentam ter, menor deve ser seu tempo de duração, isto é, diminui-se o tempo de vida útil para acelerar o circuito produtivo desses produtos.

O toyotismo fundamenta-se, na organização da força de trabalho através dos grupos de trabalho com o discurso da participação dos trabalhadores, no projeto da empresa, o que reforça a alienação do que se produz e para quem se produz, nesse sentido, se requer, sobretudo, o perfil de trabalhador engajado e disposto a alcançar os objetivos da empresa. E ainda, na introdução da informática no processo produtivo e na desconcentração produtiva, ou seja, a terceirização.

Tais fatores repercutem na intensificação das condições de exploração da mão de obra, a regra é menor contingente de força de trabalho e maiores índices de produtividade. Assim, o que ocorre é perda de direitos trabalhistas, fragmentação da classe trabalhadora, precarização da força de trabalho e destruição do sindicalismo de classe. De acordo com Antunes (2005, p. 36),

[...] o toyotismo estrutura-se a partir de um número mínimo de trabalhadores, ampliando-os, através das horas extras, trabalhadores temporários ou subcontratação dependendo das condições de mercado.

Desse modo, o toyotismo se baseia numa produção vinculada à demanda, mais individualizada, diferentemente do fordismo/taylorismo, tornandose variada e heterogênea; o trabalho operário é organizado em equipes com multivariedade de funções, onde um operário pode operar várias máquinas simultaneamente. Busca-se o melhor aproveitamento do tempo de produção (Just in time), há placas ou senhas de comando para reposição de peças ou estoque (Kanban). A estrutura produtiva é horizontalizada, transferindo-se a terceiros aquilo que não é central no processo produtivo (expansão do setor terceirizado); e por fim, há organização dos Círculos de Controle de Qualidade (CCQ) que estimulam os trabalhadores a discutir seu trabalho e desempenho.

Essa forma contemporânea de organização do trabalho enfatiza cada vez mais o processo de criação de valores de troca, impulsionando a lei de valor do capital e estimulando a consecução do trabalho flexibilizado, repercutindo na redução do trabalho vivo (homens) e expansão do trabalho morto (máquinas).
Em síntese, o processo de reestruturação produtiva do capital traz no seu bojo a passagem do modo de acumulação fordista/taylorista para o padrão de acumulação baseado nos princípios do toyotismo. Tal processo acentua a raiz da acumulação capitalista, isto é, aprofunda a exploração da classe trabalhadora, pois o trabalho estável cede lugar às formas precarizadas de trabalho configuradas na expansão do trabalho parcial, temporário, terceirizado e informal.

É importante enfatizar que concomitantemente ao processo de reestruturação produtiva na década de 1970, o movimento feminista desenvolvia um novo momento de conscientização de luta pela emancipação da mulher. A essa época, a participação das mulheres nas lutas de classe e na organização política acentuava-se, o enfrentamento ao discurso machista e conservador do papel natural da mulher como mãe e esposa ganhava força, era preciso combater a opressão das mulheres, reivindicando por sua emancipação econômica e social. Como destaca Nogueira (2004, p. 37):

\begin{abstract}
É nessa década que o combate à opressão contra mulher torna-se mais acentuado; era preciso, mais do que nunca, lutar pela sua emancipação, com todas as especificidades que isso implica, como, por exemplo, salários iguais, além da reivindicação de uma divisão mais justa no trabalho doméstico, na esfera reprodutiva, libertando ao menos parcialmente, a mulher da dupla jornada.
\end{abstract}

Assim, o padrão de acumulação flexível juntamente com o processo de desregulamentação do trabalho, iniciado a partir de 1970, ao mesmo tempo em que proporciona uma expressiva empregabilidade das mulheres revela formas precárias e vulneráveis onde elas estão frequentemente inseridas. Esse cenário de trabalho precarizado e desregulamentado tem absorvido uma significativa parcela do trabalho feminino, como mão de obra barata, ocupando funções de menor qualificação e, inseridas nos espaços marcados pela informalidade; sem mencionar que as mulheres exercem uma dupla jornada de trabalho - trabalhando dentro e fora de casa. Depreende-se então, que o capital incorpora o trabalho feminino de forma desigual, e a inserção das mulheres no mundo do trabalho como uma conquista é convertida num instrumento de desigualdade entre os sexos. Segundo as análises de Harvey (apud CARLOTO, 2002) sobre a situação das mulheres nesse contexto de flexibilização, é apontado o seguinte:

As novas estruturas de mercado de trabalho facilitam muito a exploração da força de trabalho das mulheres em ocupações de tempo parcial, substituindo trabalhadores homens 
melhor remunerados e mais difíceis de serem admitidos, pelo trabalho feminino mal pago.

Depreende-se, que o processo de acumulação flexível associado às inovações tecnológicas, configura de forma significativamente diferenciada a inserção de homens e mulheres no mundo do trabalho, isto é, as condições de trabalho se apresentam de forma distinta para os sexos. Assim, a flexibilidade do trabalho e o processo tecnológico tendem a suprimir mão de obra desqualificada por procedimentos automatizados, incidindo fundamentalmente sobre o emprego das mulheres. Isso ocorre devido ao não acesso destas à qualificação para atuar nos processos de trabalho onde se emprega alta tecnologia, expressa por uma noção existente de que elas seriam incompetentes tecnicamente, já que a especialização flexível foi construída a partir da figura de trabalhador qualificado e polivalente, reservada ao homem. De acordo, com o pontuado por Gonçalves (2003, p. 129) partindo de pesquisa realizada pela União Brasileira e Corrente Sindical revela que:

A precarização das condições de trabalho afeta bastante as mulheres na medida em que é criado um fosso entre um pequeno numero de trabalhadores qualificados e um grande número de não qualificados. Este fosso tem uma clivagem de gênero, já que as mulheres são a maioria entre os não qualificados.

Observa-se então, que o processo de feminização e masculinização das tarefas varia conforme o espaço e o tempo, esse processo coexiste com a reprodução da divisão sexual do trabalho que se mantém. Assim, as mulheres ocupam e continuam a ocupar postos de trabalho periféricos e secundários, enquanto que os homens continuam a efetuar as tarefas de maior prestígio e remuneração. Para Hirata (2002), as consequências das novas tecnologias em conjunto com a organização flexível do trabalho repercutem distintamente sobre trabalhadores e trabalhadoras, tanto nos países desenvolvidos quanto nos países em via de desenvolvimento. Dessa maneira, percebe-se que em relação à divisão sexual do trabalho, as novas tecnologias reforçam a precariedade dos postos de trabalho ocupados por mulheres; a eliminação do emprego da mão de obra feminina não qualificada e a grande ausência destas em "[...] postos técnicos e longe dos equipamentos caros e competitivos." (HIRATA, 2002, p. 231).

Portanto, verifica-se que a expansão do trabalho feminino a partir das formas contemporâneas de trabalho, baseadas na flexibilidade e na introdução de procedimentos tecnológicos, tem reservado às mulheres as ocupações mais precarizadas, trabalho subcontratado e parcial, marcado pela informalidade sem garantias sociais, pelo desnivelamento salarial, além de se subordinarem às prolongadas jornadas de trabalho.

Assistimos, então, a uma verdadeira deterioração das condições de trabalho, principalmente o feminino, contribuindo para que a sua inserção se dê em condições precárias e inseguras, com intensificação da carga de trabalho, redução da remuneração e perda de direitos sociais. Assim, a construção social da divisão sexual do trabalho, onde as formas de inserção e qualificação para o trabalho são distintas para o feminino e masculino, possibilitam o capital apropriar-se dessa desigualdade existente nas relações de gênero, por isso que a precarização das condições de trabalho tem sido mais marcante para as mulheres.

\section{CONCLUSÃO}

As profundas transformações ocorridas no fim do século $X X$ e início do século $X X I$, a partir dos processos de globalização e reestruturação produtiva, têm grandes repercussões no mundo do trabalho, incidindo fortemente sobre a classe trabalhadora e sobre suas condições de vida.

Esse cenário acarreta um processo de flexibilização da produção e das relações de trabalho, visivelmente reconhecido na precarização das condições de trabalho, que atingem de forma diferenciada homens e mulheres. Segundo Mészáros (2002), as mulheres compõem $70 \%$ dos pobres do mundo e, além de serem responsabilizadas pela reprodução social, são também as maiores vítimas da precarização das políticas públicas. E são elas as que mais estão inseridas na informalidade e nos empregos precarizados, sem garantia ou direito trabalhistas assegurados.

Nesse sentido, depreendemos que o capitalismo aprofunda e se apropria das desigualdades sociais e históricas entre os sexos e da divisão sexual do trabalho, fortalecendo-se numa ordem que discrimina em termos de gênero, classe e raça/etnia, ou ainda, conforme Saffioti (2004), a imbricação entre patriarcado, racismo e capitalismo. Sistema esse que se torna funcional para que o capitalismo se desenvolva e aprofunde sua dominação, exploração e humilhação. Portanto, apesar das desigualdades de gênero ser anterior ao capitalismo, este tem se apropriado delas mediante a consolidação de formas de vida e de inserção no mundo do trabalho que desqualificam e inviabilizam a experiência das mulheres. Dessa forma, a superação da condição das mulheres no seio dessa sociedade, só pode se realizar a medida que se supere essa forma de organização de produção e reprodução social, pautada na apropriação e acumulação de mais valia, na dominação de uma classe sobre a outra, num sistema político e ideológico de individualização, de pauperização e exclusão de grande parte da população das riquezas socialmente produzidas. 


\section{REFERÊNCIAS}

ANTUNES, R. Adeus ao trabalho?: ensaios sobre as metamorfoses e a centralidade do mundo do trabalho. São Paulo: Cortez; Campinas, SP: UNICAMP, 2005.

Os sentidos do trabalho: ensaios sobre a afirmação e negação do trabalho. São Paulo: Boitempo editorial, 2002.

ARAÚJO, Â. M. C. Ameaças aos direitos trabalhista das mulheres e a configuração de novas demandas relativas às questões de gênero. In: LIMA, M. E. B. de et al (Orgs). Transformando a relação trabalho e cidadania: produção, reprodução e sexualidade. São Paulo: CUT/BR, 2007. p. 81-101.

CARLOTO, C. M.. Gênero, reestruturação produtiva e trabalho feminino. Serviço Social em Revista, Londrina, v. 4, n. 2, jan./jun. 2002. Não paginado. Disponível em:<www.ssrevista.uel.br/c_v4n2_ carlotto.htm> Acesso em: 20 abr. 2008.

GONÇALVES, R. Dinâmica sexista do capital: feminização do trabalho precário. Revista Lutas Sociais, São Paulo, n. 9/10, p. 125-131, 2003.

HIRATA, H. A nova divisão sexual do trabalho?: um olhar voltado para a empresa e a sociedade. São Paulo: Boitempo Editorial, 2002.

MÉSZÁROS, I. Para além do capital. São Paulo: Boitempo Editorial, 2002.

NOGUEIRA, C. M. A feminização no mundo do trabalho: entre a emancipação e a precarização. Campinas, SP: Autores Associados, 2004.

SAFFIOTI, H. I. B. A mulher na sociedade de classes: mito e realidade. Petrópolis, RJ: Vozes, 1976.

Gênero, patriarcado e violência. São Paulo: Editora Fundação Perseu Abramo, 2004.

SANTOS, G. et al. Gênero e Economia Solidária: as mulheres rumo à IV plenária da economia solidária. In: FÓRUM BRASILEIRO DE ECONOMIA SOLIDÁRIA, 2007, [S. I.]. Caderno de aprofundamento aos debates. [S. I.], 2007.

\section{NOTAS}

1 Os países abrangidos pela pesquisa foram: Argentina, Brasil, Chile, México e Uruguai.

2 O padrão fordista/taylorista de produção, acumulação e reprodução da vida social caracterizava-se, fundamentalmente, pela produção em massa, homogênea e vertical; trabalho parcelado, fragmentado e cronometrado, reduzindo o processo de trabalho a um conjunto repetitivo de atividades. Serviu para aumentar a lucratividade dos patrões e a exploração dos trabalhadores e trabalhadoras, ou seja, o emprego de técnicas mecanicistas representou o máximo de desumanização do trabalho industrial.

\section{Sara Diniz Nascimento}

Assistente Social

Mestre em Políticas Públicas pela Universidade Federal do Maranhão (UFMA)

Assistente Social do Instituto Federal de Educação, Ciência e Tecnologia do Maranhão (IFMA)

E-mail: saradn@gmail.com

Instituto Federal de Educação, Ciência e Tecnologia do Maranhão - IFMA

Av. Marechal Castelo Branco, n 789, São Francisco São Luís/MA

CEP: 65076-091 